\title{
ULTRASTRUCTURE OF THE UTERINE LUMINAL EPITHELIUM AT THE TIME OF IMPLANTATION IN AGEING MICE
}

\author{
AGNES F. SMITH* \\ Department of Anatomy, The Medical School, University of Birmingham, \\ Birmingham B15 2TJ
}

(Received 22nd July 1974)

The effects of age on litter size in the mouse have been demonstrated by Jones \& Krohn (1961). Reduction in the number of living offspring produced by the ageing female precedes cessation of reproductive activity. This decline of fertility is at least partly due to an increasing incidence of embryonic death. Finn (1962) showed that more regressing embryos were found at mid-pregnancy in ageing mice than in young ones, although the total number of implantations was similar. Harman \& Talbert (1970) supported these findings when they showed that the number of ova ovulated was not appreciably reduced in older animals. The developmental potential of ova from ageing mice was compared with that of young ones by Talbert \& Krohn (1966) who found that the former compared favourably with ova from young animals. They did find, however, that the uteri of older animals were less able to maintain transplanted ova than those of young animals. This seems to be due, at least in part, to failure of blastocysts to implant, preimplantation loss being higher in the older animal (H. M. Beaumont and E. C. Jones, personal communication). With increasing age, the maternal environment appears to undergo changes which are unfavourable to the maintenance of successful pregnancies. A number of studies on the aged uterus have shown that its responses are different from those of the younger animal. Finn (1966) and Shapiro \& Talbert (1969) found a decrease in the magnitude of the decidual response in the artificially sensitized uterus of older animals. According to Shapiro \& Talbert (1969), this is first demonstrable at a time when litter size begins to decline. In similarly treated animals, the uterus did not respond with luminal closure at the time of implantation (Finn \& Martin, 1969). Finn (1970) has reviewed the research on the ageing uterus.

At the time of implantation, morphological changes in the ultrastructure of the uterus can be observed. Nilsson (1966), Potts (1968), Ljungkvist \& Nilsson (1971) and Smith \& Wilson (1974) have shown that in normal pregnancy this 'attachment stage' has a characteristic pattern. The microvilli of the luminal epithelium become organized into short irregular projections which contrast with the tall regular microvilli of the 'preattachment stage'. This change has also been observed in pseudopregnant animals (Smith \& Wilson, 1974) as well as under experimental conditions by Nilsson (1966) and Ljungkvist \&

* Present address: Department of Pathology, St Paul's Hospital, 24 Endell Street, London WG2H 9AE. 
Nilsson (1971), in which ovariectomized pregnant animals were maintained on an hormonal regimen designed to duplicate the conditions of pregnancy.

The present study examines the possibility that failure of implantation in mice may be partly due to an inability of the luminal epithelium to respond to the ovarian hormones with an 'attachment reaction'.

Sixteen C57/BL virgin mice, aged 8 to 14 months, were used. They were kept on a normal daylight schedule under standard laboratory conditions. The animals were individually caged with young males of the same strain and of proven fertility. The day the copulation plug was found was designated Day 1 of pregnancy. The animals were killed at various times between Day $4 \frac{1}{2}$ and Day 6 post coitum ( 90 to $132 \mathrm{hr}$ post coitum). The reproductive tract was exposed and examined for decidual swellings and the number was recorded. The ovaries and oviducts were fixed in Bouin's aqueous solution and processed for histological examination. Small wedges of tissue were dissected from the decidual swellings and placed into a $3.8 \%$ solution of glutaraldehyde in phosphate buffer. Portions of the uteri between swellings were also fixed. After fixation, the blocks were washed in phosphate buffer, post-fixed with buffered osmium tetroxide, dehydrated in a graded series of alcohols and embedded in resin. The blocks were cut at a thickness of $700 \AA$ on a Sorval ultratome and examined in an A.E.I. EM 801A electron microscope.

The ovaries and oviducts were dehydrated and embedded in wax, serially sectioned at $7 \mu \mathrm{m}$ and then stained with haematoxylin and eosin for light microscopy. The serial sections were used to count the number of CL of pregnancy, to observe possible abnormalities of the ovary and to determine the number of 'tube-locked' ova and those which had not been ovulated but were trapped in luteinized follicles.

Three of the sixteen animals showed no GL which could be judged as functional by the morphological criteria of Harman \& Talbert (1970) and were discarded from the experiment.

In animals with functional $C L$, the number ranged from five to sixteen. One animal had only one morphologically functional CL, while in another, though the number was normal, the CL resembled those seen on Day 2 of pregnancy rather than on Day 5, the day on which they were examined. Two animals had seven 'tube-locked' ova each. Occasional cystic follicles were seen and in a few cases only one ovary contained functional CL.

Sections of uterine tissue cut at $1 \mu \mathrm{m}$ thickness and stained with toluidine blue were also examined with the light microscope. The uterine lumen was generally open and in animals with no implantation sites, the epithelium had a corrugated appearance. The endometrial glands were sometimes tightly closed, sometimes very much enlarged.

\section{EXPLANATION OF PLATE}

Fic. 1. The luminal epithelium of a young mouse $105 \mathrm{hr}$ post coitum, showing an area adjacent to an implantation site.

FIG. 2. The luminal epithelium of a 9 -month-old mouse $105 \mathrm{hr}$ post coitum, showing an area adjacent to an implantation site. There were eleven decidual swellings.

Fig. 3. The luminal epithelium of an $11 \frac{1}{2}$-month-old mouse $108 \mathrm{hr}$ post coitum. There were no decidual swellings. 
PI ATE I

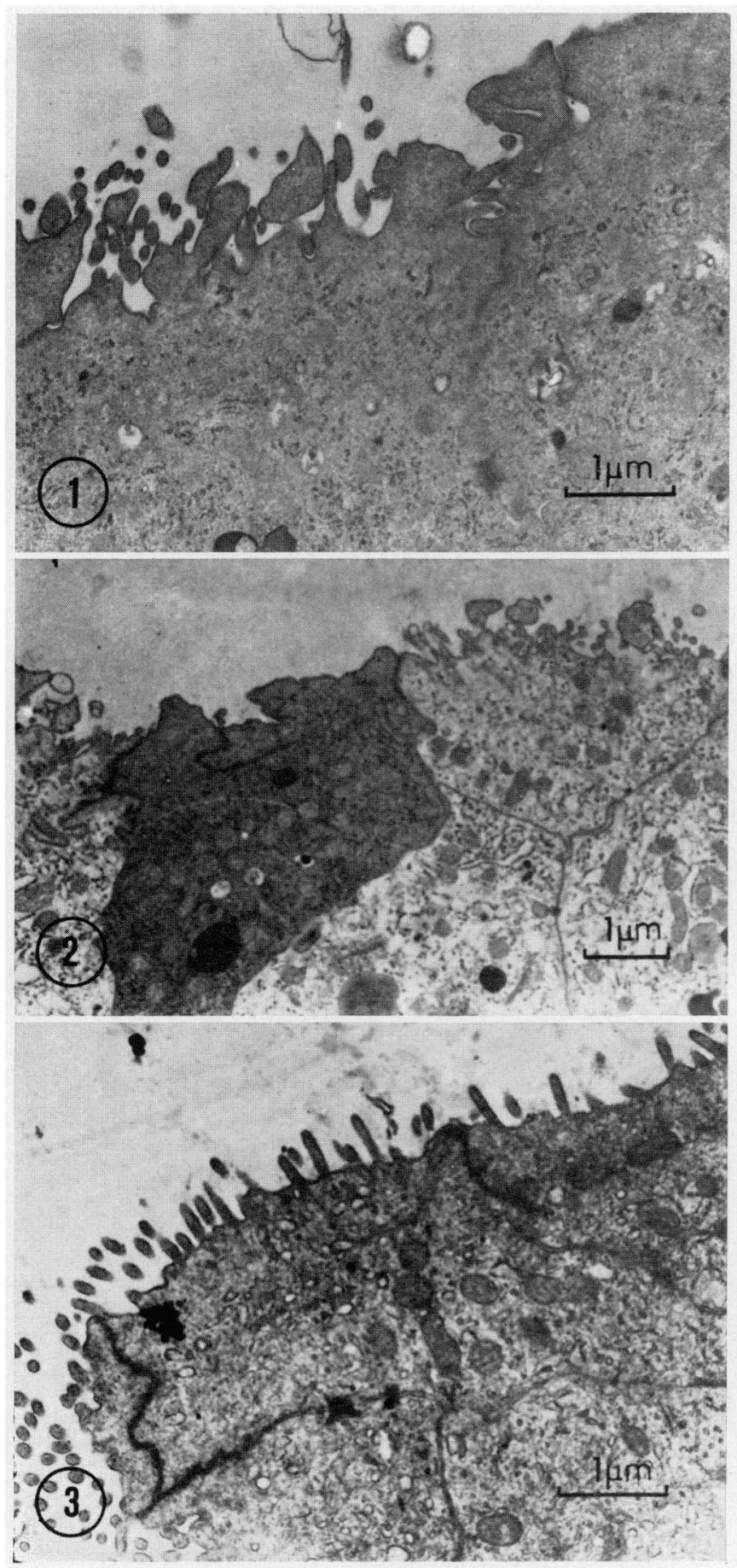

(Facing p. 184) 
Thin sections were examined under the electron microscope. There were decidual swellings in only three animals, one of which had only one swelling. Tissues taken from between swellings were compared with those taken from young pregnant and pseudopregnant animals at comparable hours after mating (Pl. 1, Figs 1 and 2).

In the ten animals which had apparently functional CL but no decidual swellings, the luminal region of the uterine epithelial cells had tall microvilli, as in the 'pre-attachment stage', though all the animals were killed after the expected time of the 'attachment reaction', between 102 and $132 \mathrm{hr}$ post coitum (Pl. 1, Fig. 3). In the animal killed at $132 \mathrm{hr}$ post coitum, the microvilli showed a similar pattern, but the cytoplasm showed much sub-lethal cell damage with greatly expanded endoplasmic reticulum, inclusion bodies, and leucocytes migrating through the epithelial layer, indicating possible alteration in the lateral attachment of the cells.

In all the animals in which implantation sites were found, the luminal epithelium of the uterus showed the characteristic 'attachment reaction', regardless of the area of the uterus from which the block had been taken, or of the number of implantation sites present. On the other hand, animals which had no implantation sites showed the typical 'pre-attachment' state of regular microvilli in all areas of the uterus. Nilsson (1966) has demonstrated that the change of the contours of the epithelial microvilli represents the response to oestrogen of a uterus primed with progesterone, and it would seem that failure of the luminal epithelium to respond to oestrogen might be one of the causes of implantation failure in the ageing mouse.

I wish to express my thanks to Dr H. M. Beaumont for advice with the manuscript and to Mr J. Wallington for photographic assistance.

\section{REFERENCES}

Fins, C. A. (1962) Embryonic death in aged mice. Nature, Lond, 194, 499.

Fins, C. A. (1966) The initiation of the decidual cell reaction in the uterus of the aged mouse. $\mathcal{F}$. Reprod. Fert. 11, 423-428.

FinN, C. A. (1970) The ageing uterus and its influence on reproductive capacity. F. Reprod. Fert., Suppl. 12, 31-38.

Fins, C. A. \& MARTin, L. (1969) The cellular response of the uterus of the aged mouse to oestrogen and progesterone. F. Reprod. Fert. 20, 545-547.

Jonks, E. C. \& KroHN, P. L. (1961) The relationships between age, numbers of oocytes and fertility in virgin and multiparous mice. F. Endocr. 21, 469-495.

Harman, S. M. \& Talbert, G. B. (1970) The effect of maternal age on ovulation, corpora lutea of pregnancy, and implantation failure in mice. 7. Reprod. Fert. 23, 33-39.

LJUNǴKVIST, I. \& NILsson, O. (1971) Ultrastructure of rat uterine luminal epithelium at functional states compatible with implantation. Z. Anat. EntwGesch. 135, 101-107.

NrLsson, O. (1966) Structural differentiation of luminal membrane in rat uterus during normal and experimental implantations. Z. Anat. EntwGesch. 125, 152-159.

Potrs, D. M. (1968) The ultrastructure of implantation in the mouse. F. Anat. 103, 77-90.

Shapiro, M. \& TAlbert, G. B. (1969) Effect of maternal age upon decidualisation. Anat. Rec. 163, 261, Abstr.

Smith, A. F. \& Wirson, I. B. (1974) Cell interaction at the maternal-embryonic interface during implantation in the mouse. Z. Zellforsch. mikrosk. Anat. (in press).

TALBERT, G. B. \& KROHN, P. L. (1966) Effect of maternal age on viability of ova and uterine support of pregnancy in mice. 7. Reprod. Fert. 11, 399-406. 